\title{
Recovery pattern of left ventricular dysfunction following radiofrequency ablation of incessant supraventricular tachycardia in infants and children
}

\author{
J V De Giovanni, A Dindar, M J Griffith, R A Edgar, E D Silove, O Stumper, JG C Wright
}

\begin{abstract}
Objective-To assess recovery pattern of left ventricular function secondary to incessant tachycardia after radiofrequency ablation in a group of infants and children.

Design and setting-A combined prospective and retrospective echocardiographic study carried out in a tertiary paediatric cardiac centre.

Patients-Echocardiographic evaluation of left ventricular size and function in nine children with incessant tachycardia, before and after successful radiofrequency ablation. Age at ablation ranged from 2 months to 12.5 years (mean 4.1 years). Recovery of left ventricular function was analysed in relation to age at ablation (group I < 18 months, group II > 18 months).
\end{abstract}

Main outcome measure-Ventricular recovery pattern.

Results-Seven of the nine children had left ventricular dysfunction; six of these also had left ventricular dilatation. All children with left ventricular dysfunction had normalisation of ejection fraction and fractional shortening; left ventricular dilatation also improved, but the improvement occurred after recovery of function. There was a shorter recovery time for left ventricular function in younger (group I) than in older children (group II) (mean (SD) $5.7 \quad$ (7.2) months $v \quad 31.3 \quad$ (5.2) $(\mathrm{p}<0.002)$.

Conclusions-Tachycardia induced cardiomyopathy is reversible following curative treatment with radiofrequency. Recovery of left ventricular systolic function precedes recovery of left ventricular dilatation. Time course to recovery is shorter in younger children.

(Heart 1998;79:588-592)

Keywords: radiofrequency ablation; left ventricular dysfunction; incessant tachycardia; echocardiography; children

Incessant or persistent supraventricular tachycardia can lead to a clinical picture of dilated cardiomyopathy with an enlarged left ventricle and reduced systolic function. ${ }^{1-3}$ The duration and the rate of the arrhythmia determine the onset of tachycardia induced cardiomyopathy. ${ }^{45}$
Reversibility of cardiac dysfunction has been shown following control of the arrhythmia ${ }^{6}$ or after successful curative treatment of the underlying substrate, either by surgery or by catheter techniques. ${ }^{8-13}$ The pattern and time scale of recovery following curative treatment of incessant tachycardia with radiofrequency ablation in children is not documented, however.

Radiofrequency (RF) ablation has been shown to be a very effective method of treatment for several types of arrhythmias in children, including the incessant forms. ${ }^{11} 12$ 14-16 Some indications for RF ablation include drug refractory or life threatening arrhythmias and haemodynamic compromise resulting from the tachycardia. ${ }^{16}$ Although there are some reservations about RF ablation in infants, ${ }^{17}$ numerous studies have shown its effectiveness and its early and medium term safety, justifying its use in certain clinical situations. ${ }^{11}{ }_{12}^{14-16} 18$

In this study we examined the pattern of recovery of left ventricular dysfunction, including the time scale to normalisation, using echocardiography in nine infants and children who had RF ablation for incessant supraventricular tachycardia.

\section{Methods}

PATIENTS

Between January 1992 and October 1996, nine children (five boys and four girls) presented with incessant tachycardia, which was unresponsive or only partially controlled by antiarrhythmic drugs (table 1). The age at presentation ranged from 1 day to 12.5 years (mean 2.3 years). Seven of the nine patients had left ventricular dysfunction; six of these also had left ventricular dilatation. The two with normal systolic function may have had diastolic dysfunction, as all the children had symptoms or signs of heart failure.

The type of tachycardia was diagnosed on the surface electrocardiogram, and the incessant or persistent nature confirmed on ward or Holter monitoring. Patients were subdivided into two groups: group I consisted of four children aged less than 18 months at the time of ablation; group II included the five older children. One patient had focal atrial tachycardia (FAT). Eight had the permanent form of junctional reciprocating tachycardia (PJRT).

\section{Group I}

All four children in this group had PJRT with cycle lengths between 280 and $360 \mathrm{~ms}$. The
Accepted for publication 16 February 1998 
Table 1 Patient data

\begin{tabular}{llllll}
\hline Patient & Sex & Age at diagnosis & Presentation & Diagnosis & Age at ablation \\
\hline 1 & M & 10 months & CHF & PJRT & 17 months \\
2 & F & Antenatal & Fetal hydrops & PJRT & 2.5 months \\
3 & F & 1 month & CHF & PJRT & 5 years \\
4 & M & 12 years & CHF & PJRT & 12 years \\
5 & M & 5 months & CHF & PJRT & 5 years 6 months \\
6 & M & 1 month & CHF & PJRT & 4 years 10 months \\
7 & F & 7 years & CHF & FAT & 7 years \\
8 & F & 1 month & CHF & PJRT & 2.5 months \\
9 & M & Antenatal & Tachycardia & PJRT & 2 months \\
\hline
\end{tabular}

CHF, congestive heart failure; FAT, focal atrial tachycardia; PJRT, permanent junctional reciprocating tachycardia. controlled with antiarrhythmic drugs and all received antifailure treatment.

TREATMENT

Electrophysiological studies were performed with parental consent under general anaesthesia. Between one and four mapping catheters were inserted through the femoral veins and, when necessary, through the subclavian vein. Group I patients only had one or two mapping catheters, one always in the His position with optional ones in the right atrium, right ventricle, left atrium, or coronary sinus. Intracardiac electrocardiograms were recorded on a CardioLab system (Prucka Engineering, Houston, Texas, USA). Ablation catheters, $5 \mathrm{~F}$ or $7 \mathrm{~F}$, were used and these had different curves and reaches, depending on the child's age. All patients were in tachycardia at the time of ablation and thus programmed stimulation was not necessary. Ablation was performed during tachycardia, using a commercial radiofrequency generator (HAT 200, Osypka, Grenzach-Wyhlen, Germany) and with the ablation catheter at the site of earliest atrial activation. Radiofrequency energy at $15-40 \mathrm{~W}$ was delivered for 10-40 seconds. Group I patients received between one and two (mean 1.5) applications of radiofrequency. The procedure was covered with heparin, and then aspirin was prescribed for three months.

Before treatment, cross sectional echocardiography had excluded structural heart disease. $\mathrm{M}$ mode echocardiography was used to assess left ventricular size and function. Left ventricular end diastolic dimension (LVEDD) and left ventricular end systolic dimension (LVESD) were measured and used to calculate ejection fraction and fractional shortening. Measurements were obtained immediately before and for a variable period after ablation until left ventricular function returned to normal.

STATISTICAL ANALYSIS

All values were expressed as mean (SD). The comparison between echocardiographic measurements and between groups on the basis of recovery time was performed using the Student's $t$ test; $\mathrm{z}$ scores $^{19}$ were calculated to express enlargement of left ventricular systolic and diastolic dimensions compared with normal values ${ }^{20} 21$ and to assess recovery of these variables independently of changes in body weight. The $\mathrm{z}$ score was calculated as [observed dimension - mean normal dimension] $\div$ standard deviation around the mean dimension.

\section{Results}

OUTCOME OF ABLATION

Ten ablation procedures were performed on the nine children. In the patient with FAT, the earliest intracardiac atrial activation was in the roof of the right atrium and measured $-29 \mathrm{~ms}$ compared with the surface $P$ wave. In the PJRT group, the tachycardia cycle length and the RP and PR intervals were 360 (52.9) $\mathrm{ms}, 227$ (19.2) ms, 132 (40.8) ms, respectively, and the
Figure 1 (A) Changes in left ventricular ejection fraction before and after radiofrequency ablation. (B) Changes in left ventricular fractional shortening before and after radiofrequency ablation. 


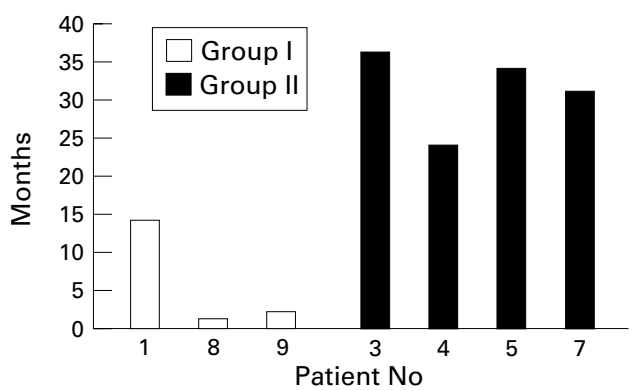

Figure 2 Time interval to recovery of left ventricular ejection fraction after radiofrequency ablation in seven children with left ventricular dysfunction.

shortest VA interval during tachycardia was in the right posterior or right posteroseptal region.

One child required a repeat procedure seven months later for early recurrence. Complete AV block occurred in two patients, transiently in one (lasting 20 seconds) and persistent in the other (the patient was aged 2.5 months at ablation), requiring permanent transvenous pacing. No other complications were encountered.

FOLLOW UP

Eight patients were in sinus rhythm and one in paced rhythm following RF ablation. The mean (SD) follow up period from the time of ablation was 13.4 (10.6) months for group I and 47.4 (10.7) months for group II.

LEFT VENTRICULAR DYSFUNCTION:

ECHOCARDIOGRAPHIC EVALUATION

Seven of the nine children $(77.8 \%)$ had left ventricular dysfunction, all of whom recovered following successful ablation. Six of these also had left ventricular enlargement (group I 50\%; group II $80 \%$ ), all of whom improved, four with full recovery at the time of writing. Two patients, one with fetal hydrops and another presenting with heart failure in infancy, had normal ventricular size and function before ablation, despite heart failure symptoms. These two were excluded from statistical analysis of recovery time in view of their normal preablation values.

Following RF ablation, left ventricular ejection fraction increased from $42.6(17.9) \%$ to $71.1(3.0) \%(\mathrm{p}<0.003)$ and shortening fraction from $19.8(8.9) \%$ to $35.2(3.15) \%$ $(\mathrm{p}<0.002)$ after a mean period of 20.7 months (fig $1 \mathrm{~A}$ and $\mathrm{B}$ ). Subgroup analysis showed a mean recovery time of 5.7 (7.2) months for group I and 31.3 (5.2) months for group II ( $\mathrm{p}<0.002)$ (fig 2$)$.

The measured LVESD and LVEDD, which were correlated with body weight, were expressed as $\mathrm{z}$ scores to take into account the expected changes in left ventricular size with the patient's growth. Figure 3 shows the $\mathrm{z}$ score changes before and at a mean of 20.7 months after the catheter ablation. The pre- and postablation $\mathrm{z}$ scores were 2.97 (2.69) and 0.5 (0.73) for LVESD $(\mathrm{p}<0.02)$ and $2.41(2.23)$ and 0.76 (1.3) for LVEDD ( $\mathrm{p}<0.07, \mathrm{NS})$.
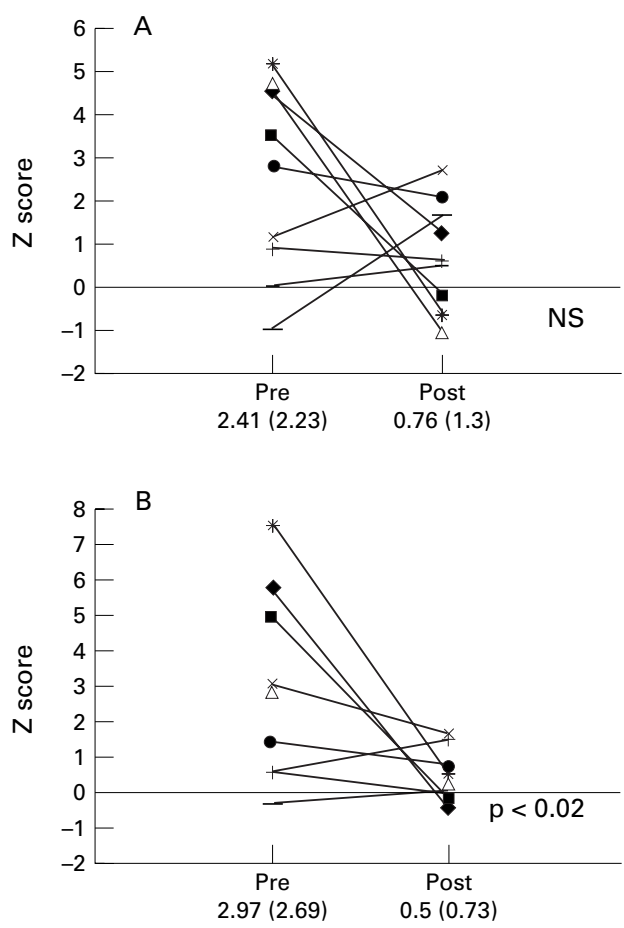

Figure 3 (A) Left ventricular end diastolic dimension before and after radiofrequency ablation, expressed in $z$ scores. (B) Left ventricular end systolic dimension before and after radiofrequency ablation, expressed in $z$ scores.

\section{Discussion}

BACKGROUND

Incessant tachycardia is a well recognised cause of "cardiomyopathy," consisting of left ventricular enlargement and impairment of systolic function. ${ }^{1-3}$ This phenomenon is particularly apparent in children in whom specific types of incessant arrhythmias, for example PJRT/FAT, are usually present in otherwise structurally normal hearts.

\section{CLINICAL AND EXPERIMENTAL DATA}

Several clinical and experimental studies have shown a causal link between the heart rate and left ventricular dysfunction. ${ }^{13222326}$ Tachycardia cycle length ${ }^{5}$ and duration of the arrhythmia ${ }^{4}$ contribute to left ventricular dysfunction. Many investigators have also observed regression of the cardiomyopathy following normalisation of heart rate in patients whose arrhythmia was either controlled ${ }^{6}$ or cured. $^{9-1128}$ There have been similar findings in experimental models (dogs and pigs) ${ }^{23}{ }^{26}$ using fast atrial pacing. Damiano et $a l,{ }^{23}$ using radionuclide angiography, reported significant reduction in ejection fraction in 13 dogs that were paced for three months at a rate of 190 beats/min. After eight weeks of pacing, there was no significant change in cardiac output or stroke volume but there was marked increase in left ventricular dimension to compensate for the reduced contraction. Moreover, five of the 13 dogs were followed up for eight weeks after the pacing period and these showed recovery of ejection fraction but left ventricular dimension remained abnormal, indicating secondary changes which do not recover immediately on control of tachycardia. Coleman et al showed 
depletion of myocardial energy stores in paced dogs, giving a plausible explanation for the left ventricular dysfunction. ${ }^{24}$ Similar studies on pigs $^{25-27}$ confirmed the haemodynamics but also showed histological and biochemical consequences of persistent tachycardia both on immature and fully grown animals. In these pig studies, persistence of left ventricular dilatation and left ventricular diastolic dysfunction following cessation of pacing indicate potentially serious changes to the myocardium, even though systolic function returned to normal and an early cure for incessant tachycardia would seem appropriate to preserve the myocardium.

\section{CURRENT STUDY: RECOVERY OF}

CARDIOMYOPATHY

Systolic dysfunction is the first manifestation of tachycardia cardiomyopathy, followed by left ventricular dilatation. Two toddlers in group I who had impaired ventricular function before ablation did not show left ventricular dilatation on the echocardiogram, whereas four of five children in group II had left ventricular dilatation; the only one in group II (patient 6) who did not show left ventricular enlargement had persistent tachycardia-that is, intermittent rather than incessant. This suggests that the longer the duration of the tachycardia, the more damaging the effect on the myocardium.

This study confirms that curing the tachycardia, in our case using RF ablation, results in resolution of the cardiomyopathy. Left ventricular systolic function, as assessed by echocardiography, recovered fully in all seven who had dysfunction before ablation. The time scale for recovery varied considerably between groups I and II, implying that the older children had worse "myocardial damage" (very likely a reflection of longer duration of tachycardia). Two children in group II (patients 4 and 5) who were initially diagnosed as suffering from primary cardiomyopathy were successfully treated for incessant tachycardia, resulting in recovery of systolic function. This recovery took up to three years; cardiac enlargement, however, persisted despite a marked improvement in LVEDD. On the other hand, two infants in group I (patients 8 and 9) who had left ventricular dysfunction but with no cardiac enlargement, showed normalisation of ejection fraction and fractional shortening within weeks of successful ablation. Thus the more advanced the cardiomyopathy, the slower and more incomplete was the recovery.

\section{AVAILABLE TREATMENT}

Ventricular dysfunction caused by incessant tachycardia does not usually improve with medical treatment. ${ }^{911}$ Curative procedures have included catheter ablation, initially using direct current and, more recently, radiofrequency or surgery. RF ablation is a recognised therapeutic curative technique for many tachycardia substrates, with a high success rate and few complications even in children. ${ }^{114-16}{ }^{29}$ Although complications have occurred, the learning curve for this relatively new technique must be taken into account. An injudicious number of radiofrequency applications, however, can inevitably lead to serious complications. ${ }^{30}$ There have only been isolated case reports of successful catheter ablation for incessant tachycardia in children with recovery of left ventricular function, ${ }^{31}$ and only one study addressing recovery time..$^{13}$ The potential long term adverse effects of RF ablation have to be balanced against the recognised effects of incessant tachycardia on left ventricular function. It was technically feasible to perform the ablation in very young children whose average weight was $4.7 \mathrm{~kg}$, and with an average of 1.5 radiofrequency applications. Complete AV block is undoubtedly a major complication. In our patient who needed a pacemaker, PJRT was abolished within three seconds of the first radiofrequency application, but junctional tachycardia led to catheter movement resulting in AV block. The use of temperature controlled ablation catheters, back up pacing, or cessation of energy delivery during junctional tachycardia may reduce this risk. None of the patients has had a recurrence of the arrhythmia over a modest follow up period, and all are asymptomatic.

\section{CONCLUSION}

Incessant tachycardia frequently causes "cardiomyopathy," resulting in left ventricular dysfunction followed by cardiac enlargement. These changes are reversible following cure of the tachycardia; however, the recovery time is related to the duration of the tachycardia, is significantly shorter in infants, and cardiac enlargement takes longer to resolve than cardiac function. RF ablation provides an effective cure for children with incessant supraventricular tachycardia and should be resorted to at an early stage, particularly if there is left ventricular dysfunction, in order to minimise myocardial damage from the arrhythmia.

1 Ferrer MI, Harvey RM. Some haemodynamic aspects of cardiac arrhythmias in man. Am Heart f 1964;68:155-65. McIntosh HD, Morris JJ. The haemodynamic consequences of arrhythmias. Prog Cardiovasc Dis 1966;8:330-60.

3 Keane JF, Plauth W, Nadas AS. Chronic ectopic tachycardia in infancy and childhood. Am Heart $\mathcal{F} 1972 ; 84: 748-57$.

4 Shachnow N, Spellman S, Rubin I. Persistent supraventricular tachycardia-case report with review of literature. Circulation 1954;10:232-6.

5 Garson A, Gillette PC, McNamara DG. Supraventricular tachycardia in children: clinical features, response to treatment, and long term follow up in 217 patients. 7 Pediatr 1981;98:875-82.

6 Kugler JD, Baisch SD, Cheatham JP, et al. Improvement of left ventricular dysfunction after control of persistent tachycardia. F Pediatr 1984;105:543-8.

7 McLaren CJ, Gersh BJ, Sugrue DD, et al. Tachycardia induced myocardial dysfunction. A reversible phenominduced myocardial dysfunction.

8 Giorgi LV, Hartzler GO, Harnaker WR. Incessant focal atrial tachycardia; a surgically remediable cause of cardiomyopathy. F Thorac Cardiovasc Surg 1984;87:466-73.

9 Pacher DL, Bardy GH, Worley SJ, et al. Tachycardiainduced cardiomyopathy: a reversible form of left ventricular dysfunction. Am $\mathcal{f}$ Cardiol 1986;57:563-70.

10 Cruz FRS, Cheriex EC, Smeets JLRM, et al. Reversibility of tachycardia-induced cardiomyopathy after cure of incessant supraventricular tachycardia. F Am Coll Cardiol 1990; 16:739-44.

11 Case CL, Gillette PC, Oslizlok PC, et al. Radiofrequency catheter ablation of incessant, medically resistant supraventricular tachycardia in infants and small children. $7 \mathrm{Am} \mathrm{Coll}$ Cardiol 1992;20:1405-10.

12 Smith RT, Gillette PC, Massumi A, et al. Transcatheter ablative techniques for treatment of the permanent form of junctional reciprocating tachycardia in young patients. $\mathcal{f}$ Am Coll Cardiol 1986;8:385-90. 
13 Fishberger SB, Colan SD, Saul JP, et al. Myocardial mechanics before and after ablation of chronic tachycardia. 1996:19:42-9.

14 Van Hare GF, Lesh MD, Scheinman M, et al. Percutaneous radiofrequency catheter ablation for supraventricular arrhythmias in children. $\mathcal{F}$ Am Coll Cardiol 1991;17:1613-20.

15 Dick M, O'Connor BK, Serwer GA, et al. Use of radiofrequency current to ablate accessory connections in children. Circulation 1991;84:2318-24.

16 Erickson CC, Walsh EP, Triedman JK, et al. Efficacy and safety of radiofrequency ablation in infants and young children < 18 months of age. Am f Cardiol 1994;74:944-7.

17 Kugler JD. Radiofrequency catheter ablation for supraventricular tachycardia. Should it be used in infants and small children? Circulation 1994;90:639-41.

18 De Giovanni JV. Treatment of arrhythmias by radiofrequency ablation. Arch Dis Child 1995:73:385-91.

19 Kirklin JW, Barratt-Boyes BG, eds. Anatomy, dimension and terminology. In: Cardiac surgery, 2nd ed. Edinburgh: and terminology. In: Cardiac

20 St John Sutton M, Mairer DL, Oldershaw PJ, et al. Effect of age-related changes in chamber size, wall thickness and heart rate on left ventricular function in normal children. .

21 Hagan AD, Deeley WJ, Sahn D, et al. Echocardiographic criteria for normal newborn infants. Circulation 1973;48 $1221-6$.

22 Ricci DR, Orlick AE, Alderman EL, et al. Influence of heart rate on left ventricular ejection fraction in human beings. Am f Cardiol 1979;44:447-51.

23 Damiano JR, Tripp HF, Asano T, et al. Left ventricular dysfunction and dilatation resulting from chronic supraventricular tachycardia. I Thorac Cardiovasc Surg 1987;94: $135-43$
24 Coleman HN, Taylor RR, Pool PE, et al. Congestive heart failure following chronic tachycardia. Am Heart f 1971;81: $790-8$

25 Spinale FG, Zellmer JL, Tomita M, et al. Relation between ventricular and myocyte remodelling with the development and regression of supraventricular tachycardia-induced cardiomyopathy. Circ Res 1991;60:1058-67.

26 Tomita M, Spinale FG, Crawford FA, et al. Changes in left ventricular volume, mass and function during the development and regression of supraventricular tachycardiainduced cardiomyopathy. Disparity between recovery of systolic versus diastolic function. Circulation 1991;83:635-

27 Tanaka R, Spinale FG, Crawford FA, et al. Effect of chronic supraventricular tachycardia on left ventricular function and structure in newborn pigs. $\mathcal{F}$ Am Coll Cardiol 1992:20: 1650-60.

28 Chen SA, Yang CJ, Chiang CE, et al. Effects of radiofrequency ablation of supraventricular reentrant tachycardia on left ventricular systolic dysfunction. $A m \mathcal{F}$ Cardiol 1993;71:471-3.

29 Kugler JD, Danford DA, Deal BJ, et al. and participating members of the Pediatric Electrophysiology Society. Radiofrequency catheter ablation for tachy-arrhythmias in chitdren and adolescents. N Engl f Med 1994;330:1481-7.

30 Saul JP, Hulse JE, De W, et al. Catheter ablation of accessory atrioventricular pathways in young patients; use of long vascular sheaths, the trans-septal approach and a retrograde left posterior parallel approach. $\mathcal{F} \mathrm{Am}$ Coll Cardiol 1993;21:571-83.

31 Sanchez C, Benito F, Moreno F. Reversibility of tachycardia induced cardiomyopathy after radiofrequency ablation of incessant supraventricular tachycardia in infants. $\mathrm{Br}$ Heart $f$ $1995 ; 74: 332-3$.

\section{Congenital morphologies of the aortic valve}

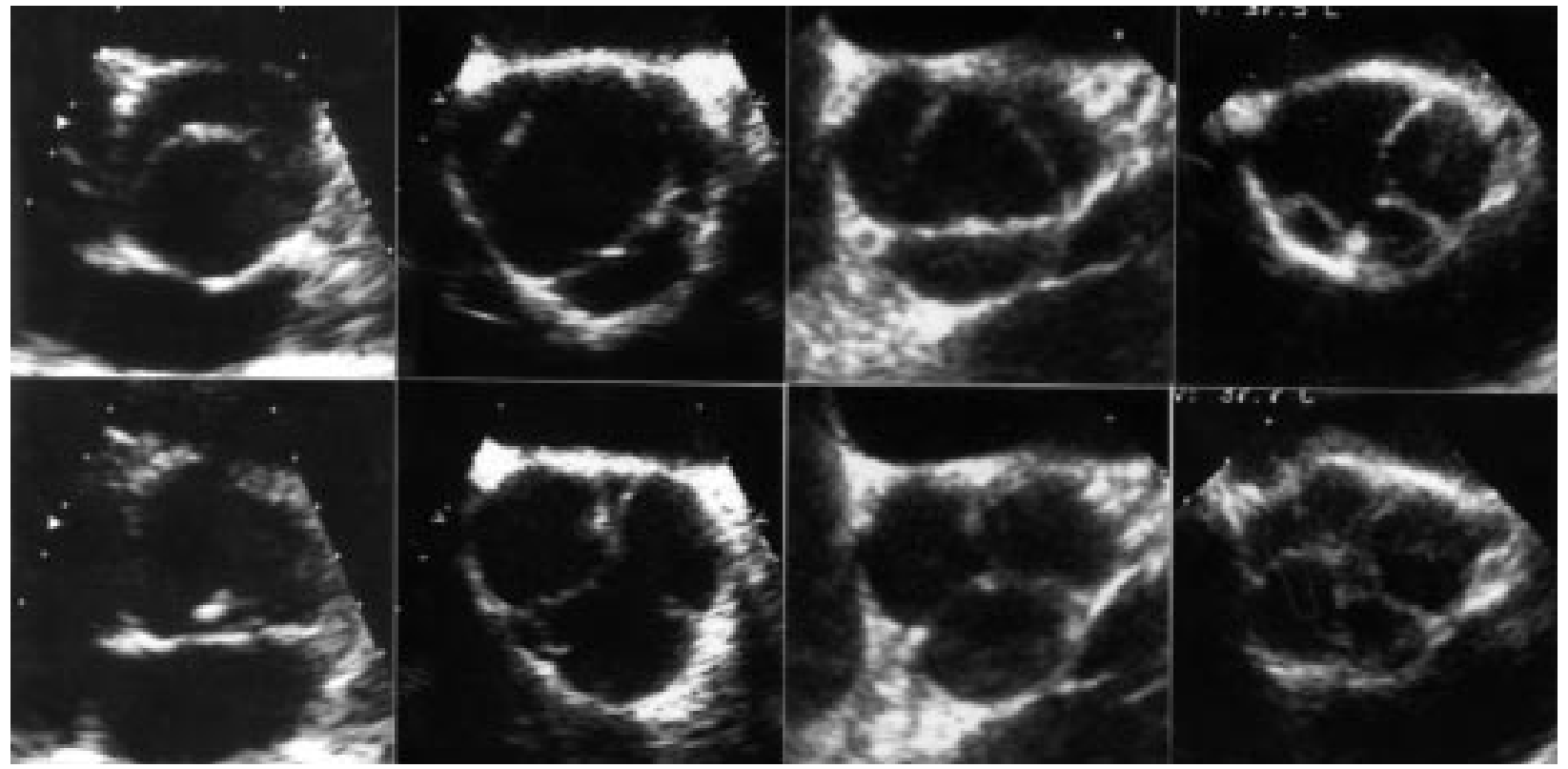

A collection of the different congenital morphologies of the aortic valve seen by echocardiography. From right to left: monocuspid, bicuspid, tricuspid, and multicuspid valves are shown with systolic view on the upper and diastolic view on the lower side. 